\title{
Enhancing reproductive performance in dairy buffalo: major constraints and achievements
}

\author{
A. S. Nanda, P. S. Brar and S. Prabhakar \\ Department of Animal Reproduction, Gynaecology and Obstetrics, Punjab Agricultural \\ University, Ludhiana 141004, India
}

\begin{abstract}
Buffalo are of high economic importance for farmers in several developing countries but reproductive performance is poor. A large proportion of heifers attain puberty at 3-5 years of age. A good quality diet supplemented with extra nutrients reduces the age of puberty, whereas the effects of administration of exogenous $\mathrm{GnRH}$ or equine chorionic gonadotrophin (eCG) are equivocal. The incidence of anoestrus in buffalo ranges from 20 to $80 \%$ depending on season. Most buffalo cease ovarian cyclicity during hot summers probably due to the combined effects of nutrition, environment and management. Keeping buffalo cool by wallowing, water sprinklers or shade improves fertility. Supplementary feeding with Urea Molasses Multi-nutrient Blocks (UMMB) for 60 days before calving enhances the early onset of postpartum oestrus. Regular UMMB supplementation also improves pregnancy rates in anoestrous non-pregnant buffalo. Prepartum vaginal prolapse is hereditary and eradication can be achieved by genetic selective breeding programmes. Treatment with calcium, phosphorus and progesterone gives only transient relief to clinical cases, Uterine torsion is the most common cause of dystocia ( $70 \%)$. Deployment of Sharma's detorsion method and anti-stress measures increase survival rates in cases presented within $36 \mathrm{~h}$. In conclusion, greater understanding about the effects of better year-round nutrition, improved management and markers for logical breeding programmes are essential to curtail the incidence of the reproductive disorders that reduce buffalo fertility.
\end{abstract}

\section{Introduction}

The water buffalo (Bubalus bubalis) is important in several developing tropical countries providing meat, milk and draught power. Indeed, this species produces about $10 \%$ of the world's total milk, of which $99.7 \%$ is produced in developing countries, an important point considering that milk constituents are higher in buffalo than cows: milk fat $(6.5-8.0 \%$ versus $3.5-4.0 \%)$ and solids-not-fat $(9.0-10.5 \%$ versus $7.5-8.5 \%)$. Furthermore, buffalo utilize poorer quality roughage, adapt to harsher environments and are more resistant to several bovine tropical diseases. 
Despite these various merits, buffalo have relatively poor reproductive efficiency that varies little with location throughout the world (Moioli et al ., 1998; Qureshi et al., 1999; Singh et al., 2000). Buffalo exhibit many of the known reproductive disorders and have delayed onset of puberty, poor oestrus expression, long postpartum ovarian quiescence and a high incidence of calving difficulties. Buffalo are usually kept in small numbers, often one to ten animals per farmer, and because they are indigenous to developing countries, there is limited scope for enhancement of reproductive performance. The main aim of this review is to describe the major constraints on reproductive efficiency, highlight recent achievements and identify areas for future research.

\section{Age at puberty}

Poor expression of oestrus makes its detection difficult; and hence, age at puberty is often extrapolated from the date of first calving. Thus, puberty in buffalo is recorded as $15-39$ months (Naqui and Shami, 1999).

The pituitary glands of 12 -month-old heifers will respond to administration of $200 \mu \mathrm{g}$ exogenous GnRH but endogenous basal plasma gonadotrophin concentrations are not established until 24 months of age (Singh and Madan, 1998). Furthermore, treatment with exogenous hormones (equine chorionic gonadotrophin (eCG) + hCG, GnRH alone or progesterone + eCG) increases the number of animals expressing oestrous behaviour but conception rates after insemination are disappointing (Singh and Madan, 2000; Barile et al., 2001). Hence, delays in the maturation of the hypothalamus pituitary axis can be overcome by stimulating follicular growth with exogenous gonadotrophins but further research is required to determine whether it is the stimulation protocol per se or the prepubertal uterus that still limits the establishment of successful pregnancies.

The onset of puberty is influenced by breed and environment, especially nutrition. Chaudhary et al. (1991) supplemented the diet of 10- to 14-month-old Nili-Ravi buffalo with concentrates to achieve a daily weight gain of $650 \mathrm{~g}$ and the onset of puberty at 23 months compared with buffalo fed green fodder ad libitum $(240 \mathrm{~g}$ and 39 months, respectively). In 8-month-old heifers of the same breed, puberty is advanced to 28 months (compared with 29.4 months in controls) by a $15 \%$ increase in concentrate supply (N. Singh, personal communication). However, overfeeding with $30 \%$ more nutrients delays sexual maturity to 35.5 months.

Clearly, puberty involves a complex interplay of endocrine factors, body development and other environmental cues. Endogenous hormones will initiate puberty only if a threshold stage of development has been attained within a permissive environment, but how this landmark is detected by the buffalo (or any other species) still requires elucidation.

\section{Control of oestrous behaviour}

Buffalo display weak signs of oestrus that are characterized by poor homosexual mounting behaviour, little mucus discharge and short duration of behavioural symptoms especially during summer months (Shah et al., 1990; Chohan, 1998; Perera, 1999). Most buffalo tend to come into oestrus in the early hours of the day, but there is also a high incidence of 'silent oestrus' (30-73\%) (Chauhan et al., 1982; Shah et al., 1990). Improved attention to oestrus detection shortens calving intervals and reduces the number of inseminations required per conception (Barkawi et al., 1998). Vulvar oedema, congested vulvar mucosa and frequent urination are common symptoms of oestrus in buffalo (Perera, 1999). However, mistakes are made and $23 \%$ of inseminations are carried out during the luteal phase of the oestrous 
cycle (A. S. Nanda, unpublished). Zicarelli et al. (1997) improved reproductive efficiency by introducing vasectomized buffalo bulls. However, this approach must weigh against the physical and financial risks of keeping bulls, plus the current reduced demand for draught power.

Manual palpation of ovarian structures per rectum is difficult, as adult ovaries are small and some follicles $>10 \mathrm{~mm}$ in diameter are easily diagnosed incorrectly as corpora lutea (Jainudeen et al., 1983). Diagnostic ultrasonography to monitor reproductive status requires considerable expense and technical expertise as well as being invasive (Baruselli et al., 1997; Manik et al., 1999). Hence, there is a need for simpler confirmatory tests of oestrus, such as inspection of cervical mucus for crystallization patterns (Agrawal and Datta 1977) or vaginal electrical resistance (VER; Gupta and Purohit 2001). High conception rates after one insemination ( $81 \%$ ) are achievable in inseminated buffalo with mucus values between 26 and $30 \mathrm{ohms} \mathrm{VER.} \mathrm{Values} \mathrm{from} 31$ to $40 \mathrm{ohms}$ are associated with atypical or no crystallization patterns and conception rates of 59 and $17 \%$, respectively.

Doka, a vernacular term in North India for the retention of milk and re-engorgement of teats, is often used as a sign for impending oestrus in buffalo. In about $90 \%$ of buffalo, doka occurs for 3-8 days before other signs of oestrus (Banerjee et al., 1989). However, the physiological significance remains obscure and warrants exploration. Tests for on the spot assessment of luteal status of cows based on milk progesterone also need further refinement for use in buffalo as the high milk fat concentration presents difficulties.

\section{Endocrinology}

Treatment of sub-oestrous buffalo with luteolytic doses of $\mathrm{PGF}_{2 \alpha}$ during the luteal phase boosts the expression of subsequent oestrus (Chauhan et al., 1982). Although peripheral endocrine profiles during the oestrous cycle are similar to those in cattle, a greater understanding of the hormonal control of reproductive behaviour is hampered by low plasma hormone values in buffalo compared with other ruminants (Batra and Pandey, 1983; Kanai and Shimizu, 1986; Moioli et al., 1998; Singh et al., 2001). Establishing a relationship between oestradiol, progesterone, GnRH and sexual receptivity will be a challenge for this species but worthwhile in light of the very poor expression of oestrus. Similar to cattle, buffalo have one, two or three follicular waves related to the variable duration of the ovarian cycle (Baruselli et al., 1997). Recruitment, selection, growth and follicular dominance needs to be understood better, as buffalo have fewer primordial follicles and a higher rate of atresia (Singh et al., 2000).

The role of various intrafollicular peptides in selection and growth of follicles has been a subject of interest for the last two decades. Insulin-like growth factor I (IGF-I) stimulates granulosa cell proliferation in buffalo and acts synergistically with FSH to promote granulosa cell activity in terms of protein and steroid synthesis (Pawshe et al., 1998). However, the relationship between other peptides and gonadotrophins with respect to oocyte maturation and follicular growth in buffalo still needs to be investigated.

\section{Postpartum anoestrus}

Postpartum anoestrus remains a major reproductive disorder in buffalo. The calving to calving interval in $48-66 \%$ of buffalo is $>14$ months as dictated by exposure to the environment and unpredictable management (Perera, 1999). Buffalo are susceptible to many stressors that seriously affect (re)productive efficiency especially daylength, high temperatures and nutritional deficiencies. 
Suckling is encouraged in buffalo to enhance calf survival rate and facilitate milk letdown, but unfortunately this practice also attenuates the neuroendocrine signals required for resumption of ovarian activity post partum (Dobson and Kamonpatana, 1986). Restricted suckling shortens postpartum anoestrus in buffalo but protocols still require refinement (Tiwari and Pathak, 1995).

The postpartum uterus influences the calving-to-conception period. A significant bacterial load results in endometritis and, thus, prolongs the breeding period (Usmani et al., 2001). Enhancing uterine contractility by administration of $\mathrm{PGF}_{2 \alpha}$ or other ecbolic agents hastens uterine involution (P. S. Mavi, personal communication). Furthermore, pre-partum immunopotentiation through supplementation with vitamin $\mathrm{E}$ plus selenium or tuberculin vaccine (BCG) decreases retention of fetal membranes, accelerates uterine involution and reduces the calving-to-first-oestrus interval in buffalo (Qureshi et al., 1997).

Basal LH concentrations gradually increase from day 2 to day 20 post partum and this increase reflects the increasing responsiveness of the pituitary gland to exogenous $\mathrm{GnRH}$ during the same period (Palta and Madan, 1995). Treatment with GnRH on day 14 after birth shortens the calving to conception interval and increases first insemination conception rates; however, responses vary with season of calving (Shah et al., 1990).

\section{Seasonal breeding patterns}

With the onset of summer (April), breeding efficiency in both young and adult buffalo is reduced, reaching a nadir in the dry hot months of May and June when approximately $80 \%$ of non-pregnant buffalo have quiescent ovaries. Silent oestrus is also more common in the hotter months than from August to January and it takes longer for ovarian cyclicity to resume after calving in the summer ( 80 additional days, $P<0.01$ ) (Singh et al., 2000). This phase coincides with longer daylength, higher ambient temperature and the scarcity of green fodder. Therefore, the precise cause of lowered fertility in summer remains unclear.

\section{Role of daylength}

Duration of daylength is negatively correlated with the proportion of buffalo showing postpartum oestrus $(r=-0.658 ; P<0.01)$. Fewer buffalo $(26-31 \%)$ exhibit oestrus under long daylength and artificial short photoperiods can be imposed to reduce this problem (Singh et al., 2000). Decreasing daylength is thus a strong determinant of onset of postpartum ovarian activity. Melatonin production is stimulated by decreasing photoperiod in buffalo and in summer anoestrous buffalo injected with $18 \mathrm{mg}$ melatonin once or twice each day come into oestrus (Hassan et al., 2000). More studies are clearly required on the regulatory role of melatonin in buffalo reproduction.

\section{Role of heat stress}

Buffalo do have limits to adaptations in extreme hot weather, probably due to black body colour and sparsely distributed sweat glands (Nair and Benjamin, 1963). Buffalo calving in cooler months have shorter calving-to-first-oestrus and calving-to-conception intervals than do buffalo calving in hotter months and high temperatures jeopardize conception rates after synchronization of oestrus by prostaglandin (Chohan, 1998; Perera, 1999; Qureshi et al., 1999). Provision of cool sheds with extra shade (average $33^{\circ} \mathrm{C}$ ) improved oestrus $(100$ versus $60 \%$ ) and conception rates ( 80 versus $13 \%$ ) compared with animals in an average environmental temperature of $41^{\circ} \mathrm{C}$ (Roy et al., 1968). Frequent wallowing and/or water sprinkling also lowers body temperature and improves reproductive efficiency (Srivastava 
et al., 1978). Thus, heat is a major factor contributing to lower reproductive potential of buffalo, although other confounding factors, such as humidity may intervene (Singh et al., 2000).

$\mathrm{LH}$ responses to exogenous GnRH are suppressed in summer anoestrous buffálo ( $\mathrm{P}$. Kumar, personal communication); conversely, plasma prolactin concentrations are two- to sixfold higher than in winter (Sheth et al,, 1978). Interestingly, a prolactin inhibitor (10 mg bromocriptine fed daily for 5 days) induced ovulatory oestrus within 21 days in $56 \%$ of summer anoestrous buffalo supporting the hypothesis that hyper-prolactinaemia could be responsible for suppression of ovarian activity (Verma et al., 1992). Controversially, plasma progesterone concentrations have been reported as both lower (Rao and Pandey, 1982) and higher during summer (Singh and Chaudhary, 1992). Clearly, a further delineation of the mechanism by which heat stress influences fertility in buffalo is required.

\section{Role of nutrition}

Well-managed and properly fed buffalo have better fertility in summer (Perera, 1999). Crude protein and metabolizable energy intakes fluctuate widely in anoestrous buffalo compared with cyclic buffalo (Qureshi et al., 2002). Buffalo maintained on lower levels of nutrition have sluggish ovarian activity and lower circulatory progesterone concentrations than wellfed buffalo (Kaur and Arora, 1984). This finding supports the concept that optimum nutrition is vital for profitable buffalo breeding.

Buffalo production is mainly carried out by marginal farmers in developing countries. A decrease in the size of land holdings, the attraction of cereal cultivation and the low economical status of the farmer limit round-the-year production of green fodder. Thus, specific feeding strategies need to be developed to exploit round-the-year potential. As an alternative source of energy and protein, a cost-effective Urea Molasses Multi-nutrient Block (UMMB) has been modified in our laboratory to use locally available agro-industrial by-products. Buffalo supplemented with UMMBs for 60 days before calving have better postpartum reproductive performance than control buffalo in terms of the interval to first postpartum ovulatory oestrus (34 versus 48 days), incidence of silent oestrus ( 11 versus $75 \%$ ) and clear mucous discharge at first postpartum oestrus (60 versus 20\%) (P. S. Brar, unpublished). Body condition score and postpartum ovulation intervals are also correlated; pre-partum buffalo supplemented with additional energy loose less body weight and resume ovarian activity earlier (Qureshi et al., 2002). Furthermore, calf birth weights improve with increasing pre-partum feeding (Usmani and Inskeep, 1989).

Regular supplementation of UMMBs early after calving also enhances production ( $8 \%$ more milk) and oestrus expression within 50 days ( 71 versus $14 \%$ ). UMMBs also induce fertile oestrus in non-pregnant anoestrous buffalo in summer and winter $(40$ and $90 \%$, respectively). In addition, the response to eCG treatment improves significantly after supplementation to deep anoestrous buffalo in winter (100 versus $83 \%$ ) and in summer (80 versus $67 \%$; B. Randhawa, R. S. Kang and A. S. Nanda, unpublished). Clearly, overall responses to improved nutrition are poorer in summer than in winter but while summer anoestrus is reduced in this way, it is necessary to determine the factors other than nutrition that might contribute toward seasonality in buffalo reproduction.

\section{Prevention and treatment of anoestrus}

In addition to measures already described, several pharmacological interventions can induce cyclic activity in anoestrous buffalo. However, in most cases, responses are variable 
Table 1. Efficacy of hormonal treatments to induce oestrus in buffalo (Bubalus bubalis) during summer anoestrus

\begin{tabular}{lcccc}
\hline & $\begin{array}{c}\text { Number } \\
\text { of buffalo } \\
\text { ovulating } \\
(\%)\end{array}$ & $\begin{array}{c}\text { Number of } \\
\text { buffalo } \\
\text { conceived } \\
(\%)\end{array}$ & Reference \\
\hline $\begin{array}{l}\text { Treatment } \\
\text { Norgestomet + 700 iu eCG }\end{array}$ & 30 & $21(70)$ & $16(53)$ & $\begin{array}{l}\text { Singh et al. (1983) } \\
\text { PRID }\end{array}$ \\
PRID + GnRH & 30 & $11(37)$ & $6(20)$ & $\begin{array}{l}\text { Singh et al. (1983) } \\
\text { Singh et al. (1984) }\end{array}$ \\
GnRH & 21 & $9(43)$ & $3(14)$ & Khurana et al. (1982) \\
& 21 & 0 & 0 & Singh et al. (1984) \\
\hline
\end{tabular}

None of the 9-20 buffalo kept as untreated controls in the above studies exhibited ovulatory oestrus. eCG: equine chorionic gonadotrophin; PRID: progesterone releasing intravaginal device.

and far from satisfactory. Treatments with GnRH or clomiphene that normally induce oestrus in cattle fail to do so in summer anoestrous buffalo (Khurana et al,, 1982; Sadasivarao and Rao, 1984; Nanda et al., 1991a). However, some merit still lies in insertion for 7-10 days of progesterone releasing intravaginal devices (PRID) or progestogen ear implants (Norgestomet) with or without subsequent treatment with eCG (Table 1). However, it must be reiterated that nutritional status and body condition score of buffalo at the time of hormonal treatments govern the efficacy of pharmacological methods to improve fertility.

\section{Prolapse of the vagina}

The risk of periparturient prolapse of genitalia is high in buffalo. Buffalo that have vaginal prolapse have significantly lower concentrations of calcium and phosphorus in the blood but corrective therapy with parenteral calcium, phosphorus or both elements induces only a temporary and partial clinical response (Nanda and Sharma, 1981; C. S. Rai, personal communication). In addition, Rai has diagnosed concurrent selenium deficiency with significantly lower concentrations in plasma and hair of affected buffalo, and supplementation with selenium results in complete recovery within one or two treatments. However, animal tissues need to be monitored carefully because there is a very narrow window between selenium deficiency and toxicity. Plasma progesterone profiles in buffalo with prolapses are normal. Nevertheless, exogenous progesterone treatment does reduce tenesmus and improves overall management of clinical cases probably by counteracting the excessive relaxation of pelvic ligaments and peri-vaginal tissue (Nanda and Sharma, 1981). We are currently examining the relationship between vaginal prolapse during late pregnancy and high oestradiol concentrations and greater oestradiol sensitivity.

A genetic origin is suggested by the repetition of the condition with successive pregnancies and the high incidence in some families. The condition has a heritability of $0.33 \pm 0.13$, and repeatability of 0.42 (Tomar and Tripathi, 1992). Thus, an organized breeding programme to cull affected lines could achieve eradication of vaginal prolapse in buffalo. Identification of genetic markers would be very valuable.

\section{Torsion of the uterus}

Uterine torsion, mainly a problem of first stage parturition, is the single major cause of difficult calvings (dystocia) in buffalo (70\%) and leads to a high rate of fetal and maternal mortality. 
The incidence of the condition in buffalo is much greater than in cows (Prabhakar et al., 1994).

\section{Aetiology of uterine torsion}

Physical trauma due to slipping on hill paths, wallowing, a sudden fall or fighting have all been considered as causes for uterine torsion. However, this has been refuted after failing to induce torsion experimentally in late pregnant buffalo by forced daily wallowing for $2 \mathrm{~h}$ or rolling with pressure on the abdomen (R. G. Aggarwal and G. M. Siddiquee, personal communications). Laboratory studies to determine the aetiology of uterine torsion in buffalo remained inconclusive. Biochemical and endocrine profiles of buffalo with uterine torsion appear to be an effect rather than the cause of the disorder. Animals that experience uterine torsion have higher circulating progesterone concentrations (Nanda and Sharma, 1986); however, histopathology of the corpus luteum reveals fibrosis and degeneration indicative of a non-functional state (S. Prabhakar and S. S. Matharu, unpublished). High progesterone concentrations in buffalo with uterine torsion could reflect adrenal responses to high levels of stress (Ghuman et al., 2002). Sex, size and presentation of the fetus have no effect on the occurrence of uterine torsion, and histopathology studies indicate that the gonads and adrenals of calves born to affected buffalo are not responsible for the occurrence of uterine torsion (G. M. Siddiquee, personal communication).

The broad ligaments are the only firm attachments that position the uterus for easy expulsion of the fetus during parturition. Post-mortem inspection reveals that genitalia from $17 \%$ of adult buffalo have poorly developed musculature in the broad ligament. Studies using histopathology show that there are fewer and smaller muscle strands with a poorly developed syncytium in buffalo with uterine torsion compared with buffalo with other forms of dystocia, Weaker broad ligaments were also observed in $25 \%$ of newly born female calves indicating a genetic origin (P. S. Brar, personal communication). Muscles in the broad ligaments originate in the region of cervix and extend to the anterior with some outward diversification. The post-cervical area is devoid of muscular support, which may explain the higher incidence of post-cervical torsion (>90\%, Prabhakar et al., 1994).

\section{Detorsion and delivery of the fetus}

The dam is caste and rolled rapidly in the direction of the torsion while the uterus is held manually in the vagina (El-Naggar, 1978). Sharma's detorsion method of applying greater constant pressure to the abdomen increases success rates to $90 \%$ in cases presented for treatment within $36 \mathrm{~h}$ (Singh and Nanda, 1996). Some buffalo require a Caesarean section after either an unsuccessful rolling or when the cervix fails to dilate. Such buffalo have a lower survival rate than buffalo directly subjected to Caesarean section (Nanda et al., 1991b; Matharu and Prabhakar, 2001). Delayed cases with apparent reabsorption of milk, a shrunken udder and recontracted pelvic ligaments are intractable especially when the cervix fails to dilate (Prabhakar et al., 1995). Multiple intracervical injections with $\mathrm{PGF}_{2 \alpha}$ do not elicit cervical dilatation although 3000 i.u. hyaluronidase injected into the cervix has facilitated dilatation after detorsion in $83 \%$ of cases (Malhotra et al., 1994).

\section{Supportive therapy}

Most buffalo that experience uterine torsion are under acute stress as reflected by very high plasma cortisol concentrations and suppressed ruminal, liver and kidney function. Tranquillization with acepromazine, chlorpromazine or diazepam fails to reduce plasma cortisol 
concentrations, in fact values remain high for much longer (18-24 h; Ghuman et al., 2002). Clearly, better anti-stress therapies are required to improve treatment and convalescence in affected buffalo.

\section{Conclusions}

Nutrition appears to have an over-riding influence on the reproductive efficiency of buffalo. Although daylength and high temperatures have some influence, their effects are more severe in malnourished animals. Buffalo are of high economic importance in several developing countries and have the added advantage that they can survive on plants that are unsuitable for consumption by the human population. However, improvements in current prevailing diets would have a significant effect on reproductive efficiency especially in terms of advancing puberty and reducing postpartum anoestrus. This would appear to be a better approach than pharmacological means that are also dependent on good nutrition.

Clinical appraisal of anoestrus is difficult in buffalo and the further developments in techniques to improve diagnosis of ovarian function and recognition of oestrus are imperative. The heritability of both vaginal prolapse and uterine torsion indicates that selective breeding programmes may be useful to eradicate both conditions particularly if a marker for the responsible genes could be identified.

The authors thank R. D. Sharma, former Additional Director of Research, Punjab Agricultural University, Ludhiana, India for his guidance in various experiments and H. Dobson, University of Liverpool, UK for her help with the manuscript.

\section{References}

Agrawal SC and Datta IC (1977) Physico-chemical properties of bovine cervical mucus at estrus Indian Journal of Experimental Biology 5 417-419

Banerjee AK, Choudhary RR and Bandopadhyay SK (1989) Temporary engorgement of teat (TET) - its relationship with occurrence of estrus in buffaloes Indian Journal of Animal Reproduction 10 166-169

Barile VL, Galasso A, Marchiori E, Pacelli C, Montemurro $\mathrm{N}$ and Borghese A (2001) Effect of PRID treatment on conception rate in Mediterranean buffalo heifers Livestock Production Science 68283 287

Barkawi AH, Khattab RM and El-Wardani MA (1998) Reproductive efficiency of Egyptian buffaloes in relation to oestrous detection systems Animal Reproduction Science 51 225-231

Baruselli PS, Mucciolo RG, Visintin JA, Viana WG, Arruda RP, Madureira EH, Oliveira CA and Molero JR (1997) Ovarian follicular dynamics during the estrous cycle in buffalo (Bubalus bubalis) Theriogenology 47 1531-1547

Batra SK and Pandey RS (1983) Luteinizing hormone and estradiol-17 $\beta$ in blood plasma and milk during the oestrous cycle and early pregnancy in Murrah buffaloes Animal Reproduction Science 5 247-257

Chaudhary MA, Asghar AA and Ahmed M (1991) Productive and reproductive performance of Nili-Ravi buffalo heifers as influenced by mineral and concentrate mixture Buffalo Journal 7 41-49

Chauhan FS, Sharma RD and Singh GB (1982) Response of different doses of $\mathrm{PGF}_{2 \alpha}$ on estrus induction, fertility and progesterone levels in subestrus buffaloes Theriogenology 17 247-253

Chohan KR (1998) Estrus synchronization with lower doses of $\mathrm{PGF}_{2 *}$ and subsequent fertility in subestrous buffalo Theriogenology $501101-1118$

Dobson $\mathrm{H}$ and Kamonpatana M (1986) A review of female cattle reproduction with special reference to a comparison between buffaloes, cows and zebu Journal of Reproduction and Fertility 77 1-36

El-Naggar M (1978) Evaluation of field oriented treatment of uterine torsion in buffaloes in Egypt Indian Veterinary Journal $\mathbf{5 5} 61-67$

Gupta KA and Purohit GN (2001) Use of vaginal electrical resistance (VER) to predict estrus and ovarian activity, its relationship with plasma progesterone and its use for insemination in buffaloes Theriogenology $56235-245$

Hassan SG, Battaway KEI, Menoufy AAEI, Younis M and Khattab RM (2000) Studies on postpartum anoestrum in Egyptian buffaloes Proceeding5, 74th International Congress on Animal Reproduction; Stockholm 1 $185-186$

Jainudeen MR, Sharifuddin $W$ and Ahmad FB (1983) Relationship of ovarian contents to plasma 
progesterone concentration in the swamp buffalo (Bubalus bubalis) Veterinary Record 113 369-372

Kanai $\mathrm{Y}$ and Shimizu $H$ (1986) Changes in plasma concentrations of luteinizing hormone, progesterone and oestradiol-17\% during the periovulatory period in cyclic swamp buffaloes (Bubalus bubalis) Animal Reproduction Science 11 17-24

Kaur H and Arora SP (1984) Annual pattern of plasma progesterone in normal cycling buffaloes fed two levels of nutrition Animal Reproduction Science 7 $32,3-332$

Khurana NK, Tyagi RPS, Gupta RC and Verma SK (1982) Gonadotropic releasing hormone in treatment of anestrus buffaloes Indian Veterinary fournal 59479 480

Malhotra P, Sharma RD, Singla VK and Pangawkar GR (1994) Effect of hyaluronidase and $\mathrm{PGF}_{2 \alpha}$ on the dilatation of cervix in buffaloes suffering from uterine torsion Indian Veterinary Medical Journal 18 46-47

Manik RS, Singla SK, Palta P and Madan ML (1999) Changes in follicular population following treatment of buffaloes with PMSG (eCG) and neutra-PMSG for superovulation Animal Reproduction Science 56 31-38

Matharu SS and Prabhakar S (2001) Clinical observations and success of treatment in buffaloes having uterine torsion Indian Journal of Animal Reproduction 22 45-48

Moioli BM, Napolitano F, Puppo S, Barile VL, Teranzo GM, Borghese A, Malfatti A, Catalano A and Pilla AM (1998) Patterns of oestrus, time of $\mathrm{LH}$ release and ovulation and effects of time of artificial insemination in Mediterranean buffalo cows Animal Science $6687-91$

Nair PG and Benjamin BR (1963) Studies on sweat glands in the Indian water buffalo Indian Journal of Veterinary Science 33 102-106

Nanda AS and Sharma RD (1981) Study on the calcium and progesterone treatment in prepartum prolapse of vagina in buffaloes Indian Journal of Animal Research $1537-40$

Nanda AS and Sharma RD (1986) Studies on serum progesterone levels in relation to occurrence of uterine torsion in buffaloes Theriogenology 26 383-389

Nanda AS, Chauhan FS and Sharma RD (1991a) Observations on oestrus, ovulation and progesterone profiles after clomiphene treatment in summer anoestrus buffaloes Buffalo Bulletin 10 27-31

Nanda AS, Sharma RD and Nowshehri MA (1991b) Outcome of various regimes of treatment of uterine torsion in bufaloes Indian Journal of Animal Reproduction 12 197-200

Naqvi AN and Shami SA (1999) Comparative performance of early and late maturing Nili-Ravi buffalo heifers Asian-Australian Journal of Animal Science $12336-340$

Palta P and Madan ML (1995) Alterations in hypophysial responsiveness to synthetic GinRH at different post- partum intervals in Murrah buffalo (Bubalus bubalis) Theriogenology 44 403-411

Pawshe CH, Rao KB and Totey SM (1998) Effect of insulin-like growth factor 1 and its interaction with gonadotropins on in vitro maturation and embryonic development, cell proliferation, and biosynthetic activity of cumulus-oocyte complexes and granulosa cells in buffalo Molecular Reproduction and Development $49277-285$

Perera BMAO (1999) Reproduction in water buffalo: comparative aspects and implications for management Journal of Reproduction and Fertility Supplement 45 157-168

Prabhakar S, Singh P, Nanda AS and Sharma RD (1994) Clinico-obstetrical observations on uterine torsion in buffaloes Indian Velerinary lournal $71822-$ 824

Prabhakar S, Dhaliwal GS, Sharma RD and Nanda AS (1995) Success of treatment in relation to milk letdown and pelvic relaxation in bovines with torsion of uterus Indian Journal of Dairy Science 48 323-325

Qureshi MS, Samad HA, Habib G, Usmani RH and Siddiqui NM (1999) Study of factors leading to seasonality of reproduction in dairy buffaloes. I. Nutritional factors Asian-Australasian Joumal of Animal Science 12 1019-1024

Qureshi MS, Habib G, Samad HA, Siddiqui MM, Ahmad $\mathrm{N}$ and Syed M (2002) Reproduction-nutrition relationship in dairy buffaloes. I. Effect of intake of protein, energy and blood metabolites levels Asian-Australasian Journal of Animal Sciences 15 330-339

Qureshi ZI, Lodhi LA and Sattar A (1997) An apparent effect of immunopotentiation during late gestation on the postpartum reproductive performance of NiliRavi buffaloes (Bubalus bubalis) Veterinary Research Communication $21375-380$

Rao LN and Pandey RS (1982) Seasonal changes in plasma progesterone concentrations in buffalo cows (Bubalus bubalis) Journal of Reproduction and Fertility 66 57-61

Roy A, Raizada BC, Tiwari RBL, Pande MD, Yaday PG and Sengupta BP (1968) Effect of management on the fertility of buffaloe-cows bred during summer Indian Journal of Veterinary Science and Animal Husbandry $38554-560$

Sadasivarao K and Rao AR (1984) Treatment of anestrus in buffaloes with certain hormones Indian Veterinary Journal $61702-707$

Shah SNH, Willemse AH and Van de Wiel DFM (1990) Descriptive epidemiology and treatment at postpartum anoestrus in dairy buffalo under small farm conditions Theriogenology 33 1333-1345

Sheth AR, Wadedekar RB, Moadbidri SB, Janakiraman $K$ and Paramesharan M (1978) Seasonal alterations in the serum prolactin and $\mathrm{LH}$ levels in the water buffaloes Current Science $4775-77$ 
Singh B, Dixit VD, Singh P, Georgie GC and Dixit VP (2001) Plasma inhibin levels in relation to steroids and gonadotrophins during oestrous cycle in buffalo Reproduction in Domestic Animals 36 163-167

Singh C and Madan ML (1998) Pituitary and gonadal responses to $\mathrm{GnRH}$ in prepubertal buffaloes AsianAustralasian fournal of Animal Science 11 78-83

Singh C and Madan ML (2000) Effects of CinRH on the plasma FSH, LH and estradiol levels at estrus induced with injection of PGF $2 \alpha$ and eCG in prepubertal buffaloes (Bubalus bubalis) Asian-Australasian lournal of Animal Sciences 13 897-900

Singh G, Singh GB, Sharma RD and Nanda AS (1983) Experimental treatment of summer anoestrus buffalo with Norgestomet and PRID Theriogenology 19323 329

Singh G, Singh GB, Sharma RD and Nanda AS (1984) Ovulation and fertility after PRID and PRID + GnRH Theriogenology $21859-868$

Singh I, Nanda AS and Adams GP (2000) The reproductive patterns and efficiency of female buffaloes Animal Reproduction Science 60 593-604

Singh N and Chaudhary KC (1992) Plasma hormonal and electrolyte alterations in cycling buffaloes (Bubalus bubalis) during hot summer months International Journal Biometeorology 36 151-154

Singh P and Nanda AS (1996) Treatment of uterine torsion in buffaloes - modification of Schaffer's method Indian Journal of Animal Reproduction 17 33-34
Srivastava RK, Dingra DP, Gangwar PC, Soni PL, Mehta SN and Singh C (1978) Effect of spray cooling and wallowing on milk yield and reproductive performance of buffaloes Journal of Agricultural Engineering 15 189-196

Tiwari SR and Pathak MM (1995) Influence of suckling on postpartum reproduction performance of Surti buffaloes Buffalo Journal 2 213-217

Tomar SS and Tripathi VN (1992) Estimates of heritability of utero-vaginal disorders in a herd of Murrah buffaloes Indian Journal of Animal Science 62 663664

Usmani RH and Inskeep EK (1989) Effect of prepartum feeding on milk yield and calf growth rate in limitedsuckled and nonsuckled buffaloes Journal of Dairy Science 72 2087-2094

Usmani RH, Ahmad N, Shafiq P and Mirza MA (2001) Effect of subclinical uterine infection on cervical and uterine involution, estrous activity and fertility in posipartum buffaloes Theriogenology $55 \quad 563-571$

Verma HK, Sidhu SS, Pangawkar GR and Dhablania DC (1992) Treatment of summer anoestrus in buffaloes with bromocriptine Indian Journal of Animal Reproduction 13 190-192

Zicarelli L, Esposito L, Campanile G, Di Palo R and Armstrong DT (1997) Effects of using vasectomized bulls in artificial insemination practice on the reproductive efficiency of Italian buffalo cows Animal Reproduction Science 47 171-180 